\title{
Development of Fluorescent Phycocyanin- $\mathrm{Cu}^{2+}$ Chemosensor for Detection of Homocysteine
}

\author{
Premsak Puangploy ${ }^{1}$, Sukunya Oaew ${ }^{2}$, Werasak Surareungchai ${ }^{{ }^{*}}$ \\ ${ }^{1}$ School of Bioresources and Technology, King Mongkut's University of Technology Thonburi, Bangkhuntien- \\ Chaitalay Road, Thakam, Bangkok 10150, Thailand. \\ 2 Biochemical Engineering and Pilot Plant Research and Development Unit, National Center for Genetic \\ Engineering and Biotechnology, National Science and Technology Development Agency at King Mongkut's \\ University of Technology Thonburi, Bangkhuntien, Bangkok 10150, Thailand.
}

${ }^{*}$ Corresponding author. Tel: +66-2-470-7474; email: werasak.sur@kmutt.ac.th

Manuscript submitted March 9, 2015; accepted May 19, 2015.

doi: 10.17706/ijbbb.2015.5.4.241-248

\begin{abstract}
A simple optical chemosensor from phycocyanin (L1), a protein-pigment complex extracted from cyanobacterium Spirulina platensis, has been developed. The L1 shows high selectivity toward $\mathrm{Cu}^{2+}$ by exhibiting spectral shift and quenching of fluorescence intensity. This $\mathrm{L} 1-\mathrm{Cu}^{2+}$ complex, so called ensemble probe, can be used to detect mercapto biomolecules, and has superior affinity toward homocysteine (Hcy). Upon binding to mercapto biomolecules, the color change from colorless to blue and the fluorescence emission change from colorless to pink were observed. This chemosensor could detect Hcy at concentration as low as $4.71 \mu \mathrm{M}(S / N=3)$ with a linear range of $10-100 \mu \mathrm{M}\left(R^{2}=0.9903\right)$. This sensing approach may have found applications in clinical diagnostics.
\end{abstract}

Keywords: Phycocyanin, copper (II) ion, mercapto biomolecules, homocysteine, turn-on fluorescence.

\section{Introduction}

Mercapto biomolecules, such as cysteine (Cys), homocysteine (Hcy), and glutathione (GSH), play essential roles in physiological processes [1]. For example, Cys is a precursor amino acid of GSH, Coenzyme A and taurine, while Hcy is critical in sulfur metabolism and methionine synthesis [2]. GSH, on the other hand, serves many cellular functions, including maintenance of intracellular redox activities, xenobiotic metabolism, and gene regulation [3]. Elevated levels of mercapto biomolecules have been linked to many diseases such as cancers and cardiovascular disease [4], [5]. However, a deficiency of mercapto biomolecules, can lead to liver damage, muscle and fat loss, and skin lesions [6], [7]. Therefore, the detection of mercapto biomolecules in biological samples is crucially important.

Several methods have been used to detect mercapto biomolecules such as spectroscopy [8], liquid chromatography [9], flow-injection [10], and electrochemical method [11], [12]. Nevertheless, all of these methods are time-consuming and difficult for on-site analyses. Moreover, they require pretreatment procedures, and use costly instruments. Among various strategies, optical methods based on colorimetric and fluorescent probes have attracted much attention due to their simplicity, high selectivity and sensitivity, low cost, and real-time monitoring [13], [14]. As the fluorometric method can reach a very low detection limit, considerable affords have been devoted to develop fluorescent probe for mercapto biomolecules in recent years [15]-[20]. However, owing to the similarity in structure and reactivity of Cys, Hcy, and GSH, 
only few fluorescent sensors with ability to discriminate these biomolecules have been reported so far [21][25].

Phycocyanin (L1) is a pigment-protein complex that captures light in cyanobacteria, rhodophytes, cryptophytes and glauphytes [26], [27]. L1 is a water-soluble protein that composes of tetrapyrole unit that functions as a chromophore. From the excellent photophysical properties such as long absorption and emission wavelength, high fluorescence quantum yield, large extinction coefficient, and high photostability, this L1 can be used as a fluorescent probe [28]. Herein, we developed a simple chemosensor for mercapto

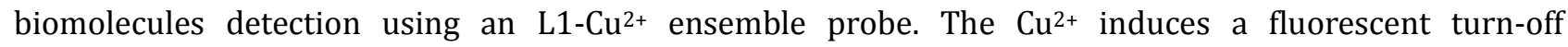
mechanism of L1 upon complexing with L1. However, the turn-on fluorescent response could be restored in the presence of mercapto biomolecules, as shown in Fig. 1. This L1- $\mathrm{Cu}^{2+}$ ensemble probe shows high selectivity toward Hcy over other amino acids and mercapto biomolecules. We speculate that the water solubility of $\mathrm{L} 1$ and metal binding affinity between $\mathrm{Cu}^{2+}$ and Hcy can effectively enhance the selectivity of the probe to Hcy, in comparison with Cys and GSH.

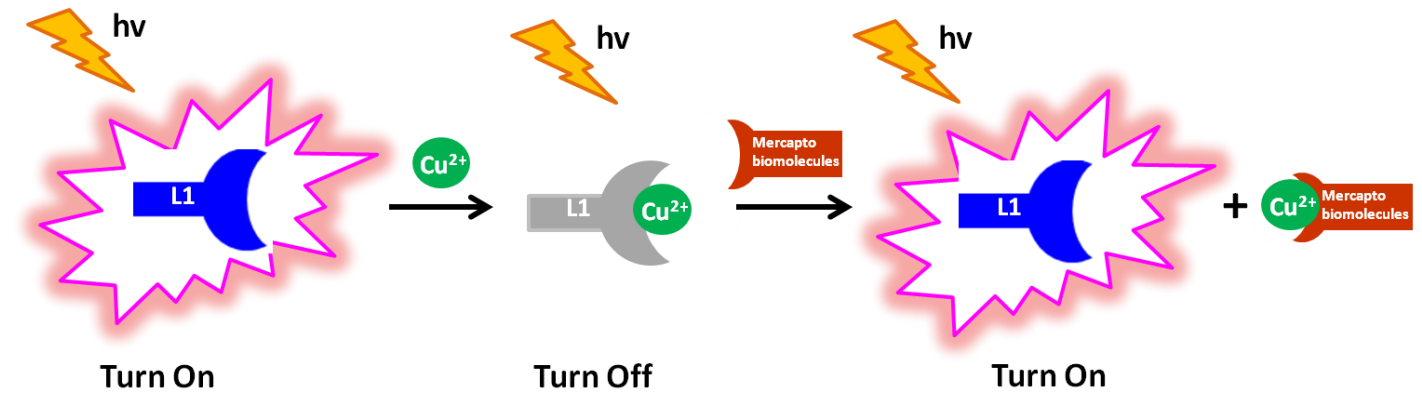

Fig. 1. Schematic drawing of the turn-on chemosensor for mercapto biomolecules detection based on L1$\mathrm{Cu}^{2+}$ ensemble probe.

\section{Experimental Section}

\subsection{Instrumentation}

Absorption and fluorescence spectra were recorded on a Tecan microplate reader. The $\mathrm{pH}$ of the solution was measured with a Mettler Toledo pH-meter. All measurements were operated at a room temperature $\left(25^{\circ} \mathrm{C}\right)$.

\subsection{Materials and Methods}

\subsubsection{Chemicals}

All chemicals were analytical grade and used without further purification. Milli Q water used throughout the experiment was purified through a Millipore system with a resistance of $18 \mathrm{M} \Omega \mathrm{cm}^{-1}$. Solution of $\mathrm{Cu}^{2+}$ was prepared from its chloride salt. All amino acids and mercapto biomolecules were purchased from Sigma-Aldrich Chemical.

\subsubsection{Preparation of $\mathrm{L} 1$ from S. platensis}

L1 was obtained from the cyanobacterium Spirulina platensis (S. platensis), a culture collection maintained at the School of Bioresources and Technology, King Mongkut's University of Technology Thonburi, Bangkok, Thailand. Extraction, separation and purification of L1 were carried out using procedures reported by Chaiklahan et al. [29]. Briefly, extraction was done by using $100 \mathrm{nM}$ phosphate buffers $(\mathrm{pH} 7.0)$ at a ratio of 1:100 (w/v) with continuous stirring at $300 \mathrm{rpm}$ at room temperature for $4 \mathrm{~h}$. 
The sample was then centrifuged at 4,800 $\mathrm{x}$ g for $15 \mathrm{~min}$ to remove the cell residue. The crude extract was firstly filtered through a $5 \mu \mathrm{m}$ membrane at flow rate of $150 \mathrm{mLmin}^{-1}$ and then through a $0.8 / 0.2 \mu \mathrm{m}$ membrane at $100 \mathrm{mLmin}^{-1}$. The phycocyanin filtrate was then filterd again through a membrane with a molecular weight cut-off of $50 \mathrm{kDa}$ at $69 \mathrm{kPa}$ and $75 \mathrm{mLmin}^{-1}$. Food-grade phycocyanin powder was obtained after lyophilization. The structure of obtained phycocyanin was shown in Fig. 2.

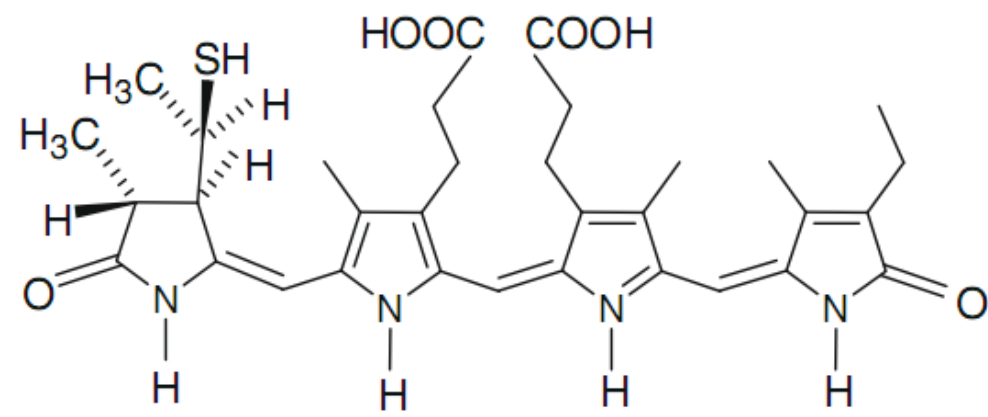

Fig. 2. Structure of phycocyanin.

\subsubsection{Preparation of stock solution}

Milli $\mathrm{Q}$ water was used to prepare metal salt solution of $\mathrm{Cu}^{2+}(10 \mathrm{mM})$ and solutions of various amino acids and mercapto biomolecules $(10 \mathrm{mM})$. L1 solution $\left(0.5 \mathrm{gL}^{-1}\right)$ was prepared in $10 \mathrm{mM}$ HEPES pH 7.0.

\subsubsection{Fluorescence measurement of $\mathrm{L} 1-\mathrm{Cu}^{2+}$ with amino acids and mercapto biomolecules}

One milliliter of $\mathrm{L} 1$ solution $\left(0.5 \mathrm{gL}^{-1}\right)$ in $10 \mathrm{mM}$ HEPES buffer ( $\left.\mathrm{pH} 7.0\right)$ was pipetted into a $2 \mathrm{~mL}$ small vial, followed by the addition of $5 \mu \mathrm{L}$ of $10 \mathrm{mM} \mathrm{Cu}^{2+}$ solution in Milli Q water. The L1- $\mathrm{Cu}^{2+}$ solution was mixed and left at $25^{\circ} \mathrm{C}$ for $15 \mathrm{~min}$. After that, $10 \mathrm{mM}$ of solution containing amino acids or mercapto biomolecules was added into the $\mathrm{L} 1-\mathrm{Cu}^{2+}$ solution for $2 \mathrm{~min}$ before the absorption and emission spectra were recorded.

\section{Results and Discussion}

\subsection{Selectivity Properties of $\mathrm{L} 1$ toward $\mathrm{Cu}^{2+}$}

\subsubsection{UV absorption and fluorescence properties of $\mathrm{L} 1$ toward $\mathrm{Cu}^{2+}$}

The absorption and fluorescence properties of $\mathrm{L} 1\left(0.5 \mathrm{gL}^{-1}\right)$ in the absence and presence of $\mathrm{Cu}^{2+}$ in $10 \mathrm{mM}$ HEPES buffer, pH 7.0 were shown in Fig. 3. The L1 was excited at wavelength $510 \mathrm{~nm}$ and showed an absorption maximum at $620 \mathrm{~nm}$, which is the characteristic of tetrapyrrole-based chromophore (Fig. 3(a)). Upon addition of $\mathrm{Cu}^{2+}$, the color of $\mathrm{L} 1$ changed from blue to colorless (Fig. 3 (a) inset), which is dued to the chelation of tetrapyrole core with $\mathrm{Cu}^{2+}$ [30]. This $\mathrm{L} 1$ also exhibited the maximum emission at $640 \mathrm{~nm}$ when excited at $510 \mathrm{~nm}$ and almost $80 \%$ of its fluorescence was quenched upon adding $\mathrm{Cu}^{2+}$, as shown in Fig. 3(b) inset.

\subsubsection{Response time of $\mathrm{L} 1$ toward $\mathrm{Cu}^{2+}$}

Once the $\mathrm{Cu}^{2+}$ was added into $\mathrm{L} 1$, the fluorescence intensity at $640 \mathrm{~nm}$ was recorded over time (0-30 min) to investigate the optimum response time of $\mathrm{L} 1$ toward $\mathrm{Cu}^{2+}$. From Fig. 4, a sharp decrease in fluorescence intensity was observed within $1 \mathrm{~min}$ after adding $\mathrm{Cu}^{2+}$ and the intensity continued to decline overtime. There was no significant change in fluorescence intensity after $15 \mathrm{~min}$. Accordingly, the 15-min response time was chosen as the optimal condition that allows maximum quenching of the L1 probe. 

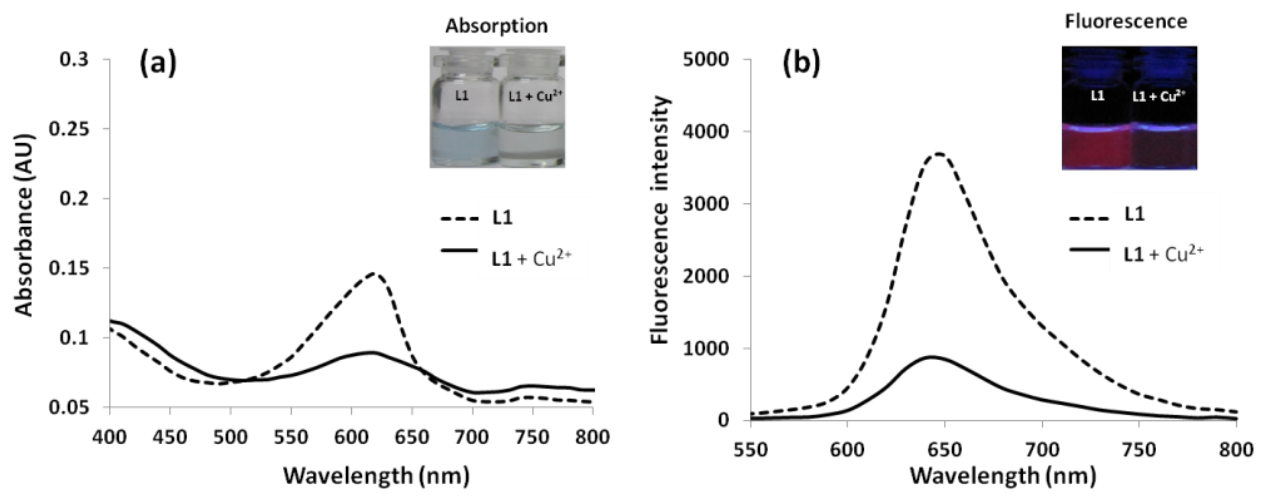

Fig. 3. (a) Absorption and (b) emission spectra of L1 (0.5 gL-1) in 10 mM HEPES (pH 7.0) in the absence and presence of $\mathrm{Cu}^{2+}(50 \mathrm{uM})$ (The insets show (a) the color and (b) fluorescence changes of L1 with and without $\mathrm{Cu}^{2+}$.

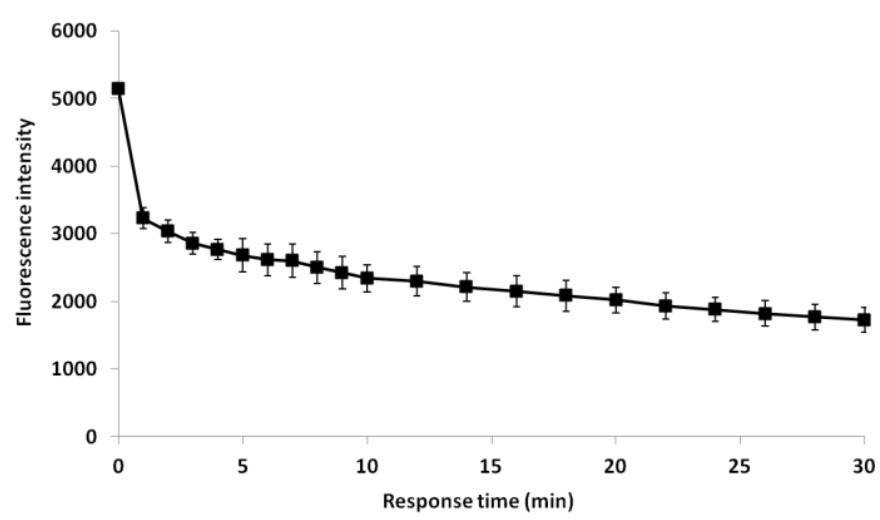

Fig. 4. Response time of $\mathrm{L} 1\left(0.5 \mathrm{gL}^{-1}\right)$ in the presence of $\mathrm{Cu}^{2+}(50 \mu \mathrm{M})$ in $10 \mathrm{mM}$ HEPES, $\mathrm{pH} 7.0$

(Fluorescence intensity was recorded at $640 \mathrm{~nm}$ ).

\subsubsection{Binding constant of $\mathrm{L} 1$ toward $\mathrm{Cu}^{2+}$}

To examine the binding constant $\left(K_{\mathrm{a}}\right)$, fluorescence titration of $\mathrm{L} 1\left(0.5 \mathrm{gL}^{-1}\right)$ was carried out with various concentrations of $\mathrm{Cu}^{2+}$ (8 to $100 \mu \mathrm{M}$ ). When the concentration of $\mathrm{Cu}^{2+}$ increased, the fluorescence intensity of L1 decreased which accompanied by a slight blue shift of $10 \mathrm{~nm}$, as shown in Fig. 5 . We estimated $K_{\mathrm{a}}$ using the emission intensity titration curve according to the equation [31]:

$$
\frac{I_{\mathrm{F}}^{0}}{\left(I_{\mathrm{F}}-I_{\mathrm{F}}^{0}\right)}=\left(\frac{1}{f}\right)\left[\frac{1}{K_{\mathrm{a}}[M]}+1\right]
$$

where $I_{\mathrm{F}}{ }^{0}$ is the fluorescence intensity of $\mathrm{L} 1$ at $640 \mathrm{~nm}, I_{\mathrm{F}}$ is the emission intensity of $\mathrm{L} 1$ at $640 \mathrm{~nm}$ upon the addition of different concentrations of $\mathrm{Cu}^{2+}, f$ is the fraction of the initial fluorescence which is accessible to the sensor, and $[M]$ is the concentration of $\mathrm{Cu}^{2+}$. In Fig. 5 inset, the data were recorded 2 min after $\mathrm{Cu}^{2+}$ being added. The inset shows the fitting of titration curve of $\mathrm{L} 1$ in the presence of $\mathrm{Cu}^{2+}(1: 1, \mathrm{v} / \mathrm{v})$. These spectra were measured in $10 \mathrm{mM}$ HEPES (pH 7.0). Excitation wavelength was $510 \mathrm{~nm}$. The $K_{\mathrm{a}}$ value is given by the ratio interception/slope and is determined to be $2.08 \times 10^{4} \mathrm{M}^{-1}$. This higher $K_{\mathrm{a}}$ value indicates a strong binding of $\mathrm{Cu}^{2+}$ to tetrapyrrole unit of $\mathrm{L} 1$, compared to an iminofluorescein- $\mathrm{Cu}^{2+}$ ensemble probe $\left(1.91 \times 10^{3} \mathrm{M}^{-1}\right)[32]$. 


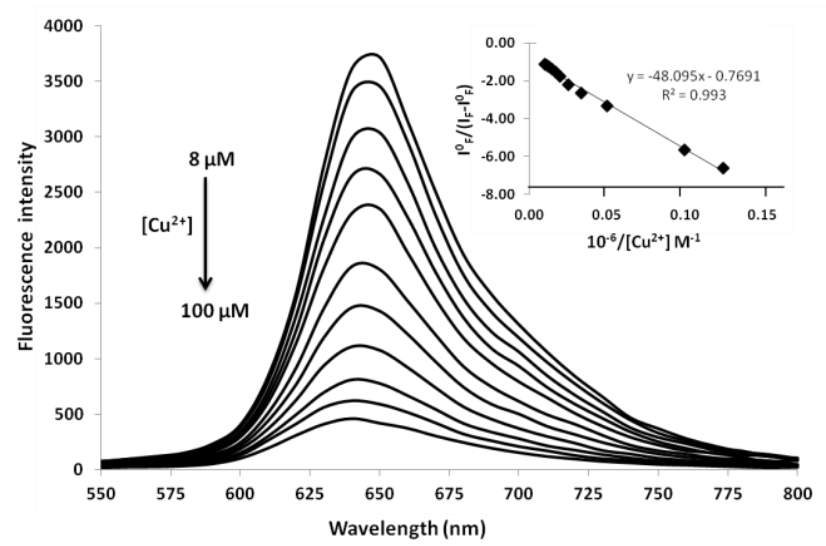

Fig. 5. Fluorescent titration spectra of $\mathrm{L} 1\left(0.5 \mathrm{gL}^{-1}\right)$ in the presence of various concentrations of $\mathrm{Cu}^{2+}$ ion $(8$, $10,20,30,40,50,60,70,80,90$ and $100 \mu \mathrm{M})$.

\subsection{Selective and Sensitive Properties of L1-Cu${ }^{2+}$ Ensemble Probe toward Mercapto Biomolecules}

\subsubsection{Selective recognition of $\mathrm{L1}-\mathrm{Cu}^{2+}$ ensemble probe}

To investigate the ability of $\mathrm{L} 1-\mathrm{Cu}^{2+}$ ensemble probe to detect mercapto biomolecules, the fluorescence emission changes of the probe were examined in terms of selectivity. The selectivity study of L1-Cu${ }^{2+}$ ensemble probe was carried out with different types of amino acids and mercapto biomolecules in $10 \mathrm{mM}$ HEPES (pH 7.0). The fluorescent intensity at 640 was recorded after applying an excitation energy at 510 nm. Among 15 amino acids and mercapto biomolecules tested, the fluorescent state of Hcy, GSH and Cys were found to restore almost completely, when compared to others (Fig. 6). Upon addition of mercapto biomolecules, we speculated that these mercapto biomolecules can remove $\mathrm{Cu}^{2+}$ from the $\mathrm{L} 1-\mathrm{Cu}^{2+}$ complex by interacting with $\mathrm{Cu}^{2+}$. Accordingly, the $\mathrm{L} 1$ is free from $\mathrm{Cu}^{2+}$ and is able to return to its original state and restore the fluorescence.

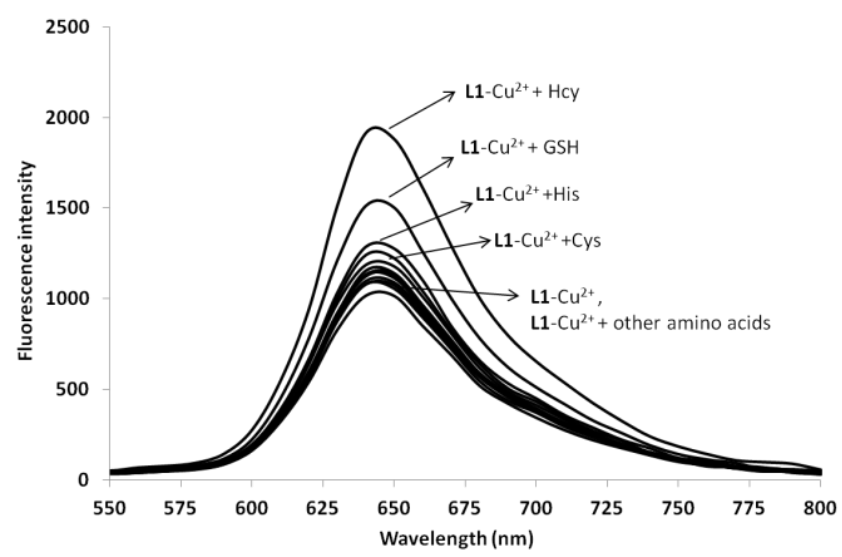

Fig. 6. The fluorescence response of $\mathrm{L} 1-\mathrm{Cu}^{2+}$ ensemble probe $(50 \mu \mathrm{M})$ in the presence of different types of amino acids and mercapto biomolcules ( $50 \mu \mathrm{M}$ of each) in $10 \mathrm{mM}$ HEPES buffer (pH 7.0) (Excitation wavelength was carried out at $510 \mathrm{~nm}$ ).

\subsubsection{Detection limit of $\mathrm{L1}-\mathrm{Cu}^{2+}$ ensemble probe toward Hcy}

To investigate the detection limit of $\mathrm{L} 1-\mathrm{Cu}^{2+}$ ensemble probe for $\mathrm{Hcy}$, various concentrations of Hcy were 
added into the probe $(50 \mu \mathrm{M})$. The fluorescence intensity at $640 \mathrm{~nm}$ was plotted against the Hcy concentrations (Fig. 7). We found a linear response of $\mathrm{L} 1-\mathrm{Cu}^{2+}$ ensemble probe toward Hcy within the range of $10-100 \mu \mathrm{M}$. This Hcy chemosensor gave a detection limit of $4.71 \mu \mathrm{M}(\mathrm{S} / \mathrm{N}=3$; \%RSD = $5.11-1.22 \%)$, which is much lower than the free intracellular Hcy concentrations (5 - $15 \mu \mathrm{M})$ [33]. Hence, this sensing system may have potential to be used in diagnosis of diseases related with abnormal levels of cellular thiols.

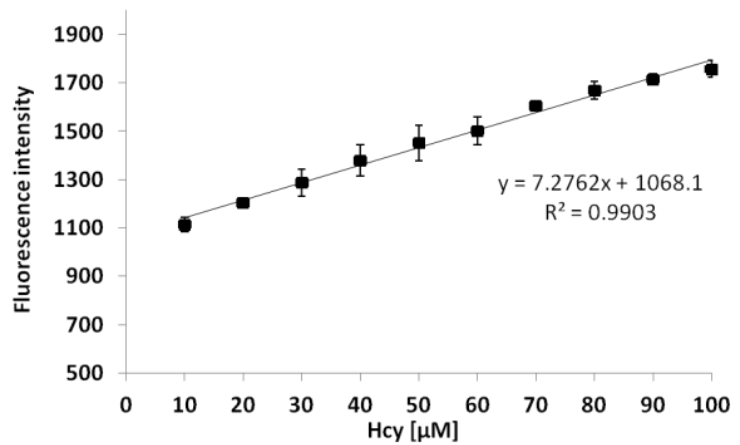

Fig. 7. Fluorescence intensity of $\mathrm{L} 1-\mathrm{Cu}^{2+}$ ensemble probe $(50 \mu \mathrm{M})$ in the presence of various concentrations of Hcy $(10-100 \mu \mathrm{M})$ in $10 \mathrm{mM}$ HEPES buffer $(\mathrm{pH}=7.0)$.

\section{Conclusion}

In summary, we have developed L1 based bifunctional fluorescence chemosensor for $\mathrm{Cu}^{2+}$ and mercapto biomolecules detection. The L1 showed high selectivity and sensitivity toward $\mathrm{Cu}^{2+}$, based on absorption and emission changes. Upon binding to $\mathrm{Cu}^{2+}$, mercapto biomolecules induced the decomplexation of $\mathrm{L} 1-\mathrm{Cu}^{2+}$ by removing $\mathrm{Cu}^{2+}$ from the $\mathrm{L} 1$ structure. This $\mathrm{Cu}^{2+}$ has high affinity for mercapto biomolecules and therefore leaves the tetrapyrole unit of $\mathrm{L} 1$ free from the $\mathrm{Cu}^{2+}$. As a result, the absorbance and fluorescent signal of $\mathrm{L} 1$ can be restored in the presence of mercapto biomolecules. Under the optimal conditions, this chemosensor can detect Hcy at concentration as low as $4.71 \mu \mathrm{M}(S / N=3)$. We believed that this water soluble L1-Cu ${ }^{2+}$ ensemble probe may have the potential to be used as a Hcy sensor in aqueous biological and medical samples.

\section{Acknowledgement}

P. P. acknowledges a Ph.D. Scholarship from Thailand's Office of the Higher Education Commission. This work was supported by the Higher Education Research Promotion and national Research University Project of Thailand in the Office of the Higher Education Commission (Grant no. 55000667).

\section{References}

[1] Cooper, A. J. (1983). Biochemistry of sulfur containing amino acids. Ann. Rev. Biochem., 52, 187-222.

[2] Yang, X., Guo, Y., \& Strongin, R. M. (2011). Conjugate addition/cyclization sequence enables selective and simultaneous fluorescence detection of cysteine and homocysteine. Angew. Chem. Int. Ed., 50, 10690-10693.

[3] Wang, H., Zhou, G., Gai, H., \& Chen, X. (2012). A fluorescein-based probe with high selectivity to cysteine over homocysteine and glutathione. Chem. Commun., 48, 8341-8343.

[4] Moreira, P. I., Harris, P. L., Zhu, X., Santos, M. S., \& Perry, G. (2007). Lipoic acid and N-acetyl cysteine decrease mitochondrial-related oxidative stress in Alzheimer disease patient fibro blasts. J. Alzheimer Dis., 12, 195-206. 
[5] Ganguly, P., \& Alam, S. F. (2015). Role of homocysteine in the development of cardiovascular disease. Nutrition Journal, 14(6), 1-10.

[6] Yang, Y. K., Shim, S., \& Tae, K. (2010). Rhodamine-sugar turn-on fluorescent probe for the detection of cysteine and homocysteine in water. Chem. Commun., 46, 7766-7768.

[7] Gazit, V., Ben-Abraham, R., Coleman, R., Weizman, A., \& Kartz, Y., (2004). Cysteine-induced hypoglycemic brain damage: An alternative mechanism to excitotoxicity. Amino Acids, 26, 163-168.

[8] Nekrassova, O., Lawrence, N. S., \& Compton, G. (2003). Analytical determination of homocysteine: A review. Talanta, 60, 1085-1095.

[9] Kusmierek, K., \& Bald, E. (2008). Reversed-phase liquid chromatography method for the determination of total plasma thiols after derivatization with 1-benzyl-2-chloropyridinium bromide. Biomed. Chromatogr., 23, 770-775.

[10] Possari, R., Carvalhal, F. R., Mendes, K. R., \& Kubota, T. L. (2006). Electrochemical deteetion of cysteine in a low syatem based on reductive desorption o thiols from gold. Anal. Chim. Acta., 575, 172-179.

[11] Shahrokhian, S. (2001). Lead Phthalocyanine as a selective carrier or preparation of a cysteineselective electrode. Anal. Chem., 73, 5872-5978.

[12] Isokawa, M., Kanamori. T., Funatsu T., \& Tsunoda, M. (2014). Analytical methods involving separation techniques or determination of low-molecular-weight biothiols in human plasma and blood, $J$. Chromatogr. B, 964, 103-115.

[13] Yan, Z., Guang, S., Xu, H., \& Liu, X. (2011). An effective real-time colorimetric sensor for sensitive and selective detection of cysteine under physiological conditions. Analyst, 136(9), 1916-1921.

[14] Puangploy, P., Smanmoo, S., \& Surareungchai, W. (2014). A new rhodamine derivative-based chemosensor for highly selective and sensitive determination of $\mathrm{Cu}^{2+}$. Sens. Actuators B, 193, 679-686.

[15] Chen, H., Zhao, Q., Wu, Y., Li, F., Yang, H., \& Huang, C. (2007). Selective phosphorescence chemosensor for homocysteine based on an iridium (III) complex. Inorg. Chem., 46, 11075-11081.

[16] Peng, H., Chen, W., Cheng, Y., Hakuna, L., Strongin R., \& Wang, B. (2012). Thiol reactive probes and chemosensors, Sensors, 12, 15907-15946.

[17] Zhou, Y., \& Yoon, J. (2012). Recent progress in fluorescent and colorimetric chemosensors or detection of amino acids. Chem. Soc. Rev., 41, 52-67.

[18] Huo, J. F., Yang, Y. T., Su, J., Sun, Y. Q., Yin, C. X., \& Yan, X. X. (2011). Indicator approach to develop a chemosensor or the colorimetric sensing of thiol-containing water and its application or the thiols detection in plasma. Analyst, 136, 1892-1897.

[19] Fu, Y., Li, H., Hu, W., \& Zhu, D. (2005). Fluorescence probes or thiol-containing amino acids and peptides in aqueous solution. Chem. Comm., 25, 3189-3191.

[20] Jung, H, S., Han, J. H., Habata, Y., Kang, C., \& Kim, S. J. (2011). An imminocoumarin-Cu(II) ensemble probe chemodosimeter toward thiols. Chem. Commun., 47, 5142-5144.

[21] Li, H., Fan, J., Wang, J., \& Peng, X. (2009). A fluorescent chemodosimeter specific for cysteine: Effective discrimination of cysteine from homocysteine. Chem. Commun., 39(39), 5904-5906.

[22] Zhang, J., Jiang, X. D., Shoa, X., \& Zhao, W. (2014). A turn-on NIR fluorescent probe for the detection of homocysteine over cysteine. RSC Adv., 96, 54080-54083.

[23] Song, L., Jia, T., Lu, W., Jia, N., Zhang, W., \& Qian, J. (2014). Multi-channel colorimetric and luorescent probes or differentiating between cysteine and glutathione/homocysteine. Org. Biomol. Chem., 12, 8422-8427.

[24] Peng, R., Lin, L., Wu, W., Liu, W., \& Feng, X. (2013). Fluorescent sensor based on BINOL or recognition of cysteine, homocysteine, and glutathione. J. Org. Chem., 78, 11602-11605.

[25] Hu, Y., Heo, H. C., Kim, G., Jun, J. E., Yin, J., Kim, M. H., \& Yoon, J. (2015). One-photon and two-photon 
sensing of biothiols using a bis-pyrene-Cu(II) ensemble probe and its application to image GSH in the cells and tissues. Anal. Chem., 87, 3308-3313.

[26] Boussiba, S., \& Richmond, E. A. (1979). Isolation and characterization of phycocyanins from the bluegreen alga Spirulina platensis. Arch. Microbiol., 120, 155-159.

[27] French, S. C., \& Young, K. V. (1951). The fluorescence spectra of red algae and the transfer of energy from phycoerythrin to phycocyanin and chlorophyll. J. Gen. Physiol., 35, 873-889.

[28] Kathiravan, A., Chandramohan, M., \& Sekar, S. (2009). Spectroscopic studies on the interaction between phycocyanin and bovine serum albumin. J. Mol. Struct., 919, 210-214.

[29] Chailahan, R., Chirasuwan, N., \& Bunnag, R. (2011). Separation and purification of phycocyanin from Spirulina sp. using a membrane process. Bioresour. Technol., 102, 7159-7164.

[30] Suresh, M., Mishra, S. K., \& Das, A. (2009). The detection of $\mathrm{Hg}^{2+}$ by cyanobacteria in aqueous media. Chem. Comm., 18(18), 2496-2498.

[31] Huang, L., Wang, X., Xie, G., Xi, P., Li, Z., Xu, M., et al. (2010). A new rhodamine-based chemosensor for $\mathrm{Cu}^{2+}$ and the study of its behavior in living cells. Dalton Trans., 39, 7894-7896.

[32] Wang, H., Zhou, G., \& Chen, X. (2013). An iminofluorescein- $\mathrm{Cu}^{2+}$ ensemble probe for selective determination of thiols. Sens. Actuators B, 176, 698-703.

[33] Refsum, H., Ueland, P. M., Nygard, O., \& Vollset, S. E. (1998). Homocysteine and cardiovascular disease. Annu. Rev. Med., 49, 1833.

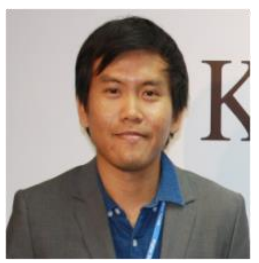

Premsak Puangploy is a Ph.D. candidate at King Mongkut's University of Technology Thonburi. He is interested in the synthesis and characterization of optical chemosensor for biological and environmental detection.

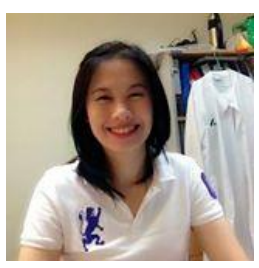

Sukunya Oaew obtained her Ph.D. degree from Imperial College London, England. Her research interests are protein and DNA biosensors for biological and medical analysis.

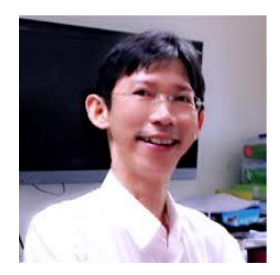

Werasak Surareungchai is an associate professor at King Mongkut's University of Technology Thonburi. His researches focus on electroanalytical chemistry and bionanotechnolgy for medical, biological, and environmental analysis. 